content in Agra by closing the power plants, switching from coal-fired locomotives to diesel in the shunting yard, moving out some of the present industries and banning from the area any new ones which might add to pollution. It also wants to set up a body to monitor the air at Agra and advise industries on how to keep within acceptable pollution limits.

The Indian Oil Corporation, which has commissioned the refinery, has also taken steps to minimise pollution. Low sulphur fuel oil and gases will be used in the furnaces, and a plant will be installed for the removal and recovery of sulphur. The height of the emission stacks will be increased from 40 metres to 80 metres to ensure better dispersal, and fixed and mobile stations will monitor the concentration of sulphur dioxide at ground level at various distances from the refinery. These measures will, according to the corporation, limit sulphur dioxide emission from the 6 million tonne refinery to 1 tonne per hour. Installing a planned flue gas desulphurisation unit could reduce this to 0.4 tonne per hour, the Corporation believes.

Corrective action is envisaged if the emissions rise above the safety level. But, critics ask, who will give directions to the refinery each time the monitoring stations give warning that the pollution has risen above the danger level? Moreover, they point out, the recommendations are not mandatory. What is the guarantee that the measures suggested by the expert committee would be fully implemented? And even if all the safeguards are taken, a certain amount of residual pollution will cause damage to the monuments over a long period.

The latest among the public figures to come out openly against the refinery is the noted ornithologist Dr Salim Ali. In a public statement he called for the shifting of the refinery as "there is a controversy among experts about its effects on the Taj". Dr Ali also spoke about the threat to the famous Bharatpur bird sanctuary near Agra because of refinery gases.

While the Government is yet to take a decision on the Varadarajan Committee report, more than 80 million rupees is reported to have already been spent on the refinery project. There is growing apprehension among critics that it may soon be too late to turn back.

\title{
India plans to invest in tethered balloon technology
}

WITH the successful ascent of a 270 cubic metre tethered balloon at the Space Applications Centre (SAC), Ahmedabad, on 19 May this year, India has joined the select band of countries like the United States, Britain and France which have developed tethered balloon technology.

According to the Electronics Commission's Information, Planning and Analysis Group, India has all the expertise and indigenous materials to develop this technology on a large scale. A panel on tethered balloon technology, set up by the commission to work out the best plan given available resources and the work in progress in the country, has recommended developing balloons of all sizes-small, medium and big. The panel has also stressed the need for making possible users aware of the potential of balloons.

Research in this technology began in India when tethered balloons were seen as a substitute for the ATS-6 satellite for the continuation of the SITE programme. On the initiative of the Electronics Commission, research was taken up at SAC in April 1974. Apart from the many government and private institutes that helped in designing and testing the balloons, collaboration was sought with the Tata Institute of Fundamental Research, where work was already in progress on plastic balloons.

Two years ago, Tata launched a similar balloon to the present one from its National Balloon Facility at Hyderabad. The present balloon is of medium size, has a payload of $50 \mathrm{~kg}$ and can float to an altitude of $1.5 \mathrm{~km}$. Except for two fireproof motors in its pressure regulation system, its components are all Indian made. It carried telemetry and telecommand equipment and batteries.

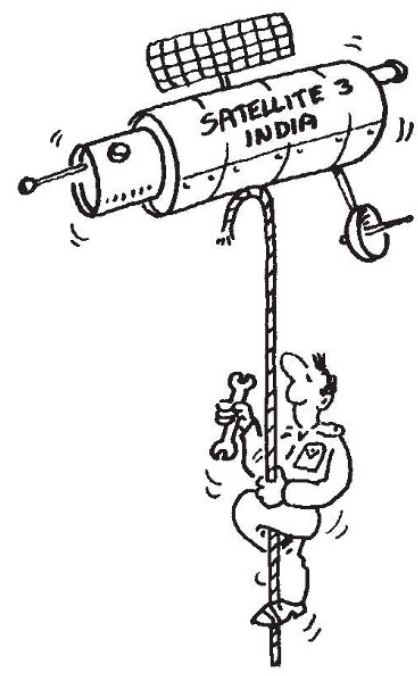

There is no doubt that tethered balloons are the poor nations' substitute for satellites. Once their technology is developed, they can be used for TV and FM broadcasting, remote sensing, ecology, oceanography, meteorology, coastline management and pollution monitoring. Because they are tethered, height can easily be varied for the study of atmospheric phenomena close to earth. A study carried out by IPAG suggests using balloons in offshore oil exploration as a temporary communication link with offshore platforms.

For communication and TV relays over hilly areas, where building earth-

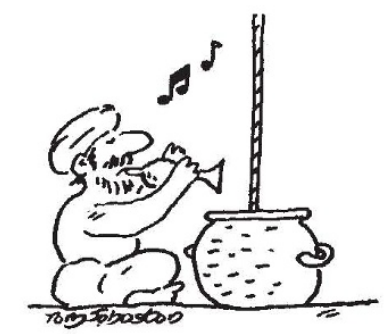

bound installations is difficult and expensive, tethered balloons can also be used. The panel has said that two balloons at an altitude of 30,000 metres, one at Shillong and another at Dibrugarh, could be easily and cheaply used for a service covering most of the north-eastern hills of India.

The panel also advocates the immediate development of low technology tethered balloons-of low payload and short flight duration. For instance, a tethered balloon with a $10 \mathrm{~kg}$ payload, parking at an altitude of $1 \mathrm{~km}$ for 24 hours, could be useful to the Meteorological Department and the Institute of Oceanography. Such balloons could also be of use in the MONEX programme scheduled for the 1979 monsoon in the country. The panel has also asked for a study of hazards to the balloons, such as lightning and ultraviolet rays.

Once the technology is fully developed, it is recommended that a national agency should take over to tailor the balloons to the needs of users. How cost effective a tethered balloon can be will be apparent from one example. For a TV broadcast operation for one per cent coverage of India, the total capital investment is 40 million rupees with an annual recurring cost 4.2 million rupees. The same costs for a tethered balloon would be 6.5 million and 1.7 million rupees.

Dilip M. Salwi

\section{Correction}

In 'India prepares to launch Earth resources satellite' (10 August, page 526) it was incorrectly stated that the $S E O$ satellite will be launched from the $S H A R$ range in India. The satellite will be launched in the Soviet Union. 